tures and the reconstruction of the obliquity of the inguinal canal, and it was for this very purpose I first employed animal sutures in 1870 . With all the emphasis of an earnest conviction, I commend to every aseptic surgeon familiarization with the methods of wound closure by means of buried absorbable sutures, preferably tendon, and not alone predict their general adoption, but believe that in importance they hold the first place in the technic of modern aseptic wound treatment.

180 Commonwealth Avenue.

\section{THE THERAPEUTICS AND SURGERY OF THE CEREBRO-SPINAL AXIS.}

Presented to the Section on Surgery and Anatomy, at the Forty-ninth Annual Meeting of the American Medical Association, held at Denver, Colo., June $7-10,1898$

BY SAMUEL KNOX CRAWFORD, M.D., IL.D. CHICAGO, ILL.

It is safe to assert that the cerebro-spinal axis is the master-wheel for man's animal machinery. If the mainspring of a watch becomes interrupted in its integrity, the gearing throughout the entire structure becomes disturbed, its functions as a chronometer cease, and it stops. If the drivewheel of a locomotive engine be impaired, the functional activity of the great iron drudge is interfered with, and the creature must rest and be repaired before activity in function can be regained. If the centerpiece of the complicated machinery of a large manufactory becomes deficient or inoperative, the whole concern must shut down for repairs at any cost. In consequence of the dangers besetting mainsprings, drivewheols and centerpieces, extra protective measures are adopted for their continuous functional activity and uninterrupted security. In most cases an alternate or duplicate is provided that functionation may be assured.

The careful student of this piece of workmanship will have observed early in his work that the law of protection and compensation has been strictly obeyed by encasing the central nervous system in the cranial and spinal cavities in two symmetric halves, the one incasement in bony pieces, endurably immovable; the other in irregular blocks endowed with enduring possibilities, all lined with tough and resisting fibrous membrane of remarkable endurance, closely adherent to the inner surface of the bones and outer walls of cavities, and for the most part furnishing profective sheaths to the outgoing nerve trunks-adherence most marked where dangers are most threatened at the sutures within the skull, but secure throughout the entire extent of both cavities. This is familiarly known to anatomists as the dura mater, from its enduring qualities. Immediately surrounding the medullary mass and intimately investing it, is a delicate membrane composed of vascular netting, threads of which, larse and small, penetrate the mass and form plexuses on the walls of the cavity within. This webbing of blood-vessels becomes plainly the nutrient mother of the system, and is hence called pia mater. Between the two maters hangs another membrane, clelicate in its fibrous structure and somewhat adherent to both. Its suspensory, lubricating and protective functions are plainly in evidence. This is the arachnoid membrane, and it serves in a triple capacity.

Epitomized, the membranous structures of the axis may properly be stated to be: the dura mater, for protection; the arachnoid, for suspension and the accommodation of movement, and the pia mater, for the accomplishment of the essential act of life - its nutrition.

Between the maters is the arachnoidian spuce and membrane with communication throughout the entire extent of the axis. Another fact may be stated withsut argument. The cerebro-spinal axis is a hollow organ itself from end to end, and the vascular netting passes through and forms an anastomosis on the walls of the lumen. Schiff, Quincke, Leightheim, Fuerbringer and others have clearly demonstrated that lumbar puncture can be practiced with more or less impunity, and that, as a diagnostic measure, the operation is of great value, enabling the diagnostician to locate with accuracy the approximate position of certain pathologic processes in meningeal affections. The admitted impunity with which the procedure may be accomplished lends assurance of safety in establishing permanent fistulæ in the lumbar, dorsal, cervical, or even in the cranial regions, as is done in the various abdominal localities for establishment of artificial anus, so efficient in many surgical measures for the relief of disorders of the intestines. Because of the dangers from infection by perverted natural discharges from the intestines, the abdomen would be the more critical field to invade.

No more vitalizing agent has been created than oxygen, and no more active and unerring antiseptic agency has been, or ever will be, devised than ozone, which is electrically condensed oxygen. In all diseases of the central nervous system the first indication is to remove the inevitable pressure, whether from the effusion of blood or of serum or from bony environment, either' from deformity or depressed bony spiculæ of traumatism, infection or vitiated nutrition.

The next move in the process of therapeutic procedure is to correct by every means at command this disturbed nutrition, which is constantly in evidence in all morbid processes. Direct medication is the modern advance in therapentic procedures as illustrated in antisepsis. Through a permanent fistulous opening at any point throughout the extent of the cerebro-spinal axis may be injected safely and with facility, a stream of oxygen or ozone into the interior of the mass, and therefore brought to bear directly on the plexuses, and thence into as intimate relation with the floating column of corpuscles as in the air cells of the lungs, and doubtless with the same vitalizing effect, or the gaseous current may be directed into the arachnoidian space and thus be brought to bear in the same way and with equal efficiency on the vascu. lar structure of the pia mater.

With a tissue as highly endowed with facilities for a constant supply of nutritive fluid as in the central nervous system, and charged with the all-important functions in evidence in it, a theory consigning it to be hopeless destruction and irretrievable ruin on every occasion when circumstances of traumatism or infection present is phenomenally absurd. Any part of the cerebro-spinal axis whose special function may be suspended for a sufficient length of time to afford rest and opportunity for a correction of interrupted nutri. tition may be safely invaded by the surgeon's knife, and repair as confidently expected as from mutilations in any other part of the body, with liberal margins in favor of the nerve mass and the bones entering into its encasements.

At the beginning of a great war with a foreign foe, whose chief historical characteristic is cruelty, and shaking from our national policies the isolations and 
conservatisms of the past to become aggressively civ-| the globe-shaped hemispherical upper extremity of ilizing, if not, indeed, cosmopolitan or imperial, with the femur.

all that these new national movements involve, I These circumstances, different in minor degree in appeal to the science of surgery and the brilliant different individuals, alter the angle of junction at array of American operators on behalf of the human the neck with the shaft somewhat, but in a way that brain, the central nervous system, or the cerebro- makes it quite evident that there is a maximum spinal axis. I make this appeal the more earnestly, and minimum degree of angularity between which knowing as I do, that thousands of the flower and extremes the angle of junction presented by any promise of our manhood must fall before the foes given specimen of the bone may be said to be norupon whom we must move in the sacred cause of mal. humanity.

Modern warfare inflicts ten wounds about the head and face to one below the waist. The field for operative procedure and therapeutic study for the military surgeon is above the waist in large degree, and in this the head and face prevail or er all others, and the reasons for this are plain, when we consider the manner of offense and defense. The military surgeon of today has opyortunity long and wide for making him. self an important factor in the march of the world in behalf of civilization and in the interests of humanity

AN INQUIRY INTO THE NORMAL ANGLE OF JUNCTION OF THE NECK, WITH THE SHAFT OF THE FEMUR.

Presented to the Section on Surgery and Anatomy at the Forty-ninth Innual Meeting of the American Medical Association, held at Denver, Colo., June 7-10, 1898.

BY M. H. SEARS, M.D

PROFESSOR OF DESCRIPTIVE ANATOMY COLORADO COLLEGE OF DENTAL SUEGERY AND LATE ADJUNCT ANATOMIST OF MEDICAL DEPARTMENT UNIVERSITY OF COLORADO. DENLER, COLO.

In the examination of this subject, an effort has been made to confine the inquiry to specimens of the male bone fully developed, free from the results of injury or disease, and ranging in age as nearly as could be determined from twenty-five to forty years.

These extremes of age are selected arbitrarily, for between these periods of life the bone may be said to be at the height of its development-it has neither the deficiencies of incomplete growth or the defects of degeneration incident to age; it may be presumed therefore to be typical in all of its detail. As is well known, two angles are formed by the neck of the femur with the shaft of the bone, the upper being an acute angle, while the lower is an obtuse angle and gentle curve from the lower portions of the neck to the internal border of the shaft with which it becomes continuous. The arrangement of the bonv fiber of the neck and the position of the neck itself upon the shaft is undoubtedly for minimizing the strain of the bodily weight above, in its transmission to the upper extremity of the bone below. These facts are now generally well recognized. It will also not have escaped the notice of the observer that the trochanter minor acts as an additional and powerful support to the neck of the femur upon its posterior and internal aspects, assisting greatly in transmitting the bodily weight. Again the perpendicular diameter of the base of the neck is greatly increased, as compared with the transverse measurements of the bone at the same place, also for the natural purpose, quite evidently of compensating for the change in direction of the strain of the bodily weight by increased strength and quantity of bony structure, the change in direction being from a perpendicular line to an angular line passing from the cup-shaped cotyloid cavity to

In order to arrive at conclusions worthy of credence some definite method of anatomic measurement dependent upon fixed anutomic relations should be devised. When these relations varied in any given specimen of the bone which I examined, it was noticed that the angle of junction also varied in a like proportional degree, but always within the extremes of angularity above alluded to as probably being normal. In selecting specimens of the bone from which measurements were made for the purposes of this paper; those bones were chosen which presented on the anterior surface a large venous foramen-usually much larger than its neighbors--which was placed immediately below the spiral line and in a position which seemed to be the anatomic center of the shaft. Through this opening a perpendicular line was projected, which was also parallel to the axis of the shaft as nearly as could be determined. The position of the foramen in the specimens selected seemed also to be placed about one-sixth of an inch below the anatomic center of the neck of the bone, for the reason that a line projected through the center of the neck and representing its axis-as nearly as could be determined-intersected the line of the axis of the shaft at one-sixth of an inch above the foramen, thus establishing perhaps the true angles by which a bone should be measured. The two angles established are an upper acute and a lower obtuse angle. After establishing these angles and marking them upon the several bones examined by use of ink, they were carefully examined and measured with an angleometer, an instrument of precision for exact measurements of this character. In some twenty-five or thirty specimens examined-a number not sufficient to establish fixed rules, however - the minimum acute angle measured was 38 degrees, while the maximum acute angle was 52 degrees, the average angle being 47 degrees and 30 minutes, there being a few minutes less or additional as the case might be in many of the bones examined. When the place of the foramen varied from the position of one-sixth of an inch below the spiral line, but still maintained what seemed to be the anatomic centers of the neck and shaft with reference to that line, it was noticed that the acuity of the angle became less, thus if the foramen was placed at one-fifth or onefourth of an inch below the line, the acuity of the lesser angle approached the minimum angle of 38 degrees, which has been named as the minimum angle noticed in this series of specimens. It is, of course, unnecessary to remark that the greater or obtuse angle is to be found by subtracting the measurements of the acute angle from the measurement of the axis of the shaft of the femur, which was assumed to be 180 degrees.

As is indicated by the title of this brief paper, its purpose is to record merely the results of an inquiry. The method adopted to attain these results is offered to the Section upon its merit for what it is worth.

McPhee Building, Denver, Colo. 